\title{
Notes on the vocalizations of Northern Wren (Troglodytes troglodytes)
}

\section{Peter Boesman}

In the following we briefly analyze and compare voice of the different races of Northern Wren (Troglodytes troglodytes). We also try to quantify the extent of any vocal differences using the criteria proposed by Tobias et al. (2010), as a support for taxonomic review. We have made use of sound recordings available on-line from Xeno Canto (XC).

\section{Group 1: Eurasian Wren}

Typical song includes several different series of loud repeated notes and a single almost insect-like very fast trill (the latter may also be absent in some cases).

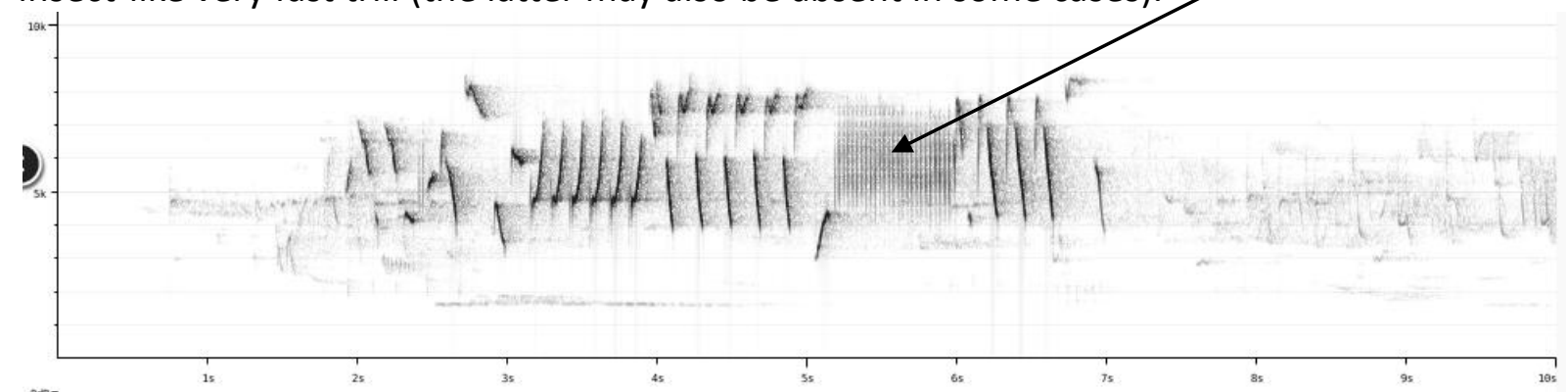

\section{Group 2: Winter Wren}

Typical song consists of many different loud short whistles and has very few series of repeated notes. Many notes have a small frequency range.

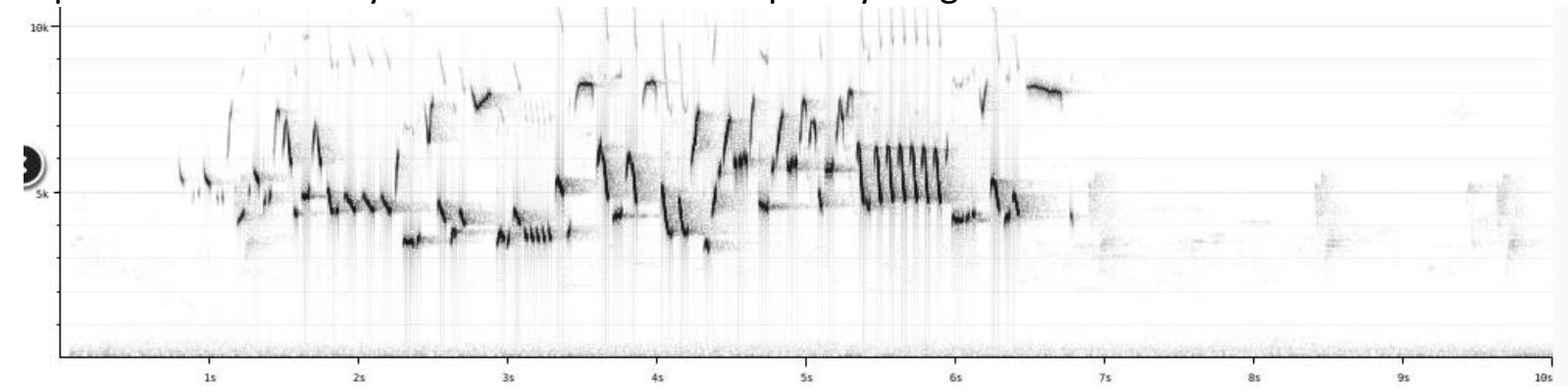

\section{Group 3: Pacific Wren}

Typical song is almost a continuum of different fast repeated notes series or very fast trills.

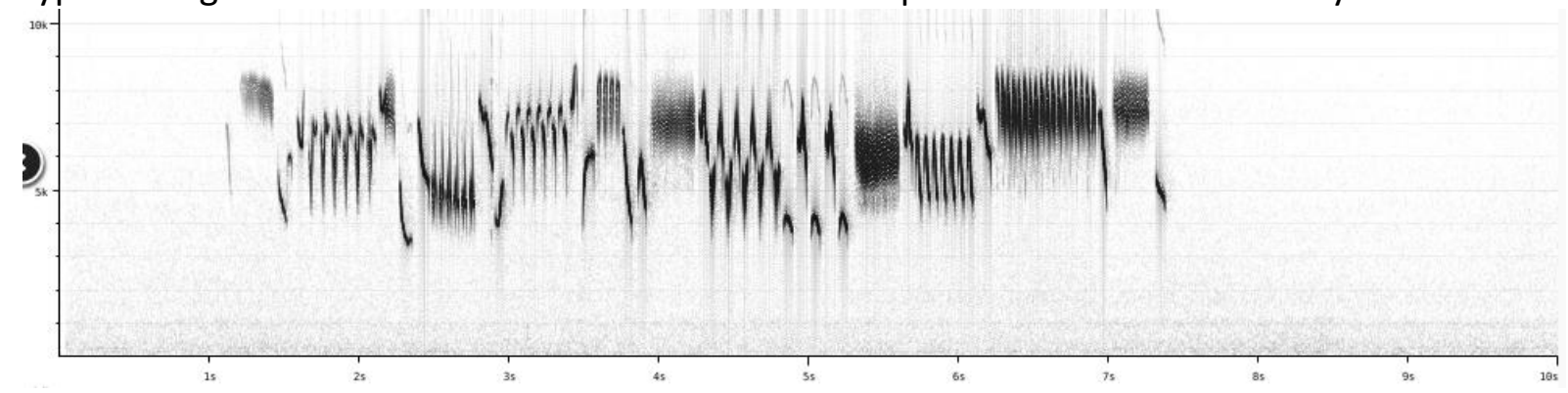



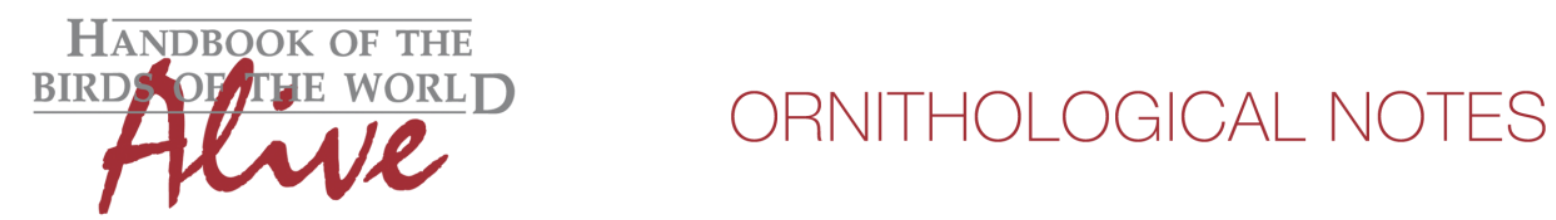

Vocal differences between Pacific and Winter Wren have been discussed in literature (Toews et al. 2008), but this study did not include comparison with the Old World races (Eurasian Wren). Similarly, call notes of the two New World groups have been discussed, see e.g. http://earbirding.com/blog/archives/774.

While there is some variability among the many Old World taxa, the vocal differences in song mentioned above are fairly constant. Differences could be quantified based on e.g. \# of repeat series in a song phrase, average pace of repeats, $\%$ of song phrase which consists of repeats, average frequency range of notes etc.

For call notes a similar exercise could be done, as at least for the two New World groups, differences have been clearly demonstrated ('tsip' for Pacific Wren vs lower-pitched 'chup' for Winter Wren, and both clearly different from typical 'trr' call notes of Eurasian Wren in W Europe).

Song of Winter Wren differs from the two other groups in having the lowest number of repeat series (score 3), lowest average frequency range of individual notes (score 2), and at least different pitch and length of call note vs Pacific Wren (score 2-3).

Pacific Wren differs from Eurasian Wren in having a higher number of repeat series per song phrase (score 2-3) and a higher average pace of repeats (score 2-3).

The three groups thus differ vocally in many ways, with measurable sound parameters leading to total vocal scores of about 5 in pair-wise comparisons.

Within the Eurasian Wren group, some subgroups may also have specific vocal features, but at first sight differences are a level less important than between the above three groups.

Further study is however recommended.

This note was finalized on 14th April 2016, using sound recordings available on-line at that moment. We would like to thank in particular the many sound recordists who placed their recordings for this species on XC.

\section{References}

Tobias, J.A., Seddon, N., Spottiswoode, C.N., Pilgrim, J.D., Fishpool, L.D.C. \& Collar, N.J. (2010). Quantitative criteria for species delimitation. Ibis 152(4): 724-746.

Toews, D.P.L. \& Irwin, D.E. (2008). Cryptic speciation in a Holarctic passerine revealed by genetic and bioacoustic analyses. Mol. Ecol. 17: 2691-2705. 


\section{Recommended citation}

Boesman, P. (2016). Notes on the vocalizations of Northern Wren (Troglodytes troglodytes). HBW Alive Ornithological Note 283. In: Handbook of the Birds of the World Alive. Lynx Edicions, Barcelona. (retrieved from http://www.hbw.com/node/1251725 on 11 October 2016). 